\title{
Development and Organization of the Aerial Mycelium in Streptomyces coelicolor
}

\author{
By H. WILDER MUTH* \\ John Innes Institute, Norwich, NOR 7oF \\ (Accepted for publication 30 September 1969)
}

SUMMARY

The anatomy of individual colonies of Streptomyces coelicolor was studied at various developmental stages in situ by means of surfaceimpressions and thin sections. Young colonies consisted of substrate mycelium composed of a loose network of hyphae with uniform appearance. The uppermost cells produced the very closely packed hyphae of the aerial mycelium. Subsequently the surface layer of the aerial mycelium began to sporulate but became overgrown by young hyphae which formed a new sporulating zone above the first. The process was repeated several times. Many of the early produced spores germinated immediately. When the climax of sporulation was reached the aerial mycelium showed two trends of development: one towards spore formation (in the surface layer) and one towards lysis of non-sporulating hyphae (below the sporulating zone). Sporulation was initiated by coiling of hyphal tips which were then divided by cross walls into chains of spore-sized compartments. The basal nonsporulating parts of the hyphae disintegrated later. The most conspicuous cytological change during lysis was the appearance of large dense granules.

\section{INTRODUCTION}

It is characteristic of Streptomycetes growing on solid media to produce two sorts of mycelium: substrate and aerial (Waksman, 1959). A germinating spore forms substrate hyphae which branch frequently and grow radially, developing into a young colony. Subsequently the aerial mycelium is produced. In a study by phase-contrast microscopy Hopwood (1960) confirmed the observations of Erikson (1949) that the aerial hyphae of Streptomyces coelicolor originated by simple branching from substrate hyphae and not necessarily from fusion cells as claimed by Klieneberger-Nobel (1947) for Streptomyces gardneri, Streptomyces albosporeus, Streptomyces chromogenes and Streptomyces madurae. Nevertheless the results of genetic studies (Hopwood, I967) suggested that fusion of substrate hyphae, or some kind of conjugation between them, occasionally occurs.

The fine structure of the aerial mycelium in various Streptomycetes as seen in thin sections has been studied by several authors (Hagedorn, 1960; Glauert \& Hopwood, I959, I960, I96I; Hopwood \& Glauert, I960; Rancourt \& Lechevalier, I964; Bradley \& Ritzi, 1968). However in these studies mycelium was unsystematically scraped from colony-surfaces, centrifuged and then prepared for electron microscopy, or, if whole colonies were sectioned, no attempt was made to obtain information on the development and spatial organization of individual colonies. The present

* Present address: Zoologisches Institut der Universität Zürich, 8006 Zürich, Switzerland. 
report describes a study of the changes in fine structure of the aerial and the adjacent parts of the substrate mycelium of Streptomyces coelicolor in situ during the development of the colony. Fine structure of the sporulation process is described in an accompanying paper (Wildermuth \& Hopwood, 1970).

\section{METHODS}

Stock cultures of wild-type Streptomyces coelicolor A 3 (2)(Streptomyces violaceoruber according to Kutzner \& Waksman, 1958) and an adenine/histidine requiring mutant (strain 504, hisE6, of the Hopwood stock culture collection) were maintained at $30^{\circ}$ on a complex agar medium-'complete medium' (Hopwood, 1967). The auxotrophic mutant, which grows slowly on minimal medium, produced tiny compact colonies $(0.4$ to I $\mathrm{mm}$. in diameter at 7 days) when grown on unsupplemented, chemically defined 'minimal medium' (Hopwood, 1967). These were more suitable for anatomical studies of whole colonies than were the much larger ones of the wild type. Single colonies of both strains at various stages of growth on 'minimal medium' were cut out of the agar and prefixed for $2 \mathrm{hr}$ in ice cold $2.5 \%(\mathrm{v} / \mathrm{v})$ glutaraldehyde in cacodylate buffer at $\mathrm{pH} 7 \cdot 2$ (Glauert \& Thornley, 1966; Audrey M. Glauert, personal communication). The vessel in which the prefixation was performed was partially evacuated by means of a water pump to expel the air trapped between the hydrophobic aerial hyphae. Colonies were postfixed at room temperature overnight at atmospheric pressure in $1 \%(\mathrm{w} / \mathrm{v})$ osmium tetroxide in veronal-acetate buffer at pH 6.I (Ryter \& Kellenberger, I958), washed for $2 \mathrm{hr}$ in Ryter-Kellenberger buffer containing $0.5 \%(\mathrm{w} / \mathrm{v})$ uranyl acetate, dehydrated in a graded ethyl alcohol series and embedded in Araldite (Glauert \& Glauert, 1958). Thin sections were cut on an LKB Ultratome III with glass knives and mounted on carbon- or formvarcoated copper grids. Specimens were examined in a Siemens Elmiskop Ia, operating at 60 or $80 \mathrm{kV}$ at instrumental magnifications between 4,000 and 20,000 .

Negatively stained specimens were prepared as follows. The surface of a colony was gently touched with a carbon-coated grid and the impression negatively stained with $\mathrm{I} \%(\mathrm{w} / \mathrm{v})$ aqueous potassium phosphotungstate $(\mathrm{pH} 7)$ or $2 \%(\mathrm{w} / \mathrm{v})$ ammonium molybdate (pH 7) (Brenner \& Horne, 1959; Horne, 1965). Unstained impressions were prepared in the same way on cover slips for viewing in the phase-contrast microscope.

\section{RESULTS}

Stages in the development of the aerial mycelium. Although environmental variation was minimized the development and final size of the individual colonies varied considerably. In the course of this work it was found that both features depended largely on the depth of the medium and on the population density of the colonies. However unknown factors also influenced the growth of individual colonies considerably, so that it was difficult to estimate the physiological age of a colony; both absolute age and colony diameter proved unsuitable. The most reliable indicator of physiological age was the colour of the aerial mycelium. In a systematic study it was found that colonies of the same colour (but not necessarily of the same age) exhibited rather uniform features in impressions and in sections. However a colony sometimes did not change colour simultaneously over its whole surface. Moreover in 
uniformly coloured colonies the thickness of the aerial mycelium varied considerably, the colony often appearing very flat with a diffuse edge. In order to exclude any factor which might affect the uniformity of the results unnecessarily, only compact colonies with a sharp edge and simultaneous change of colour were selected for this study. After such a selection the sections of colonies of the same colour appeared entirely uniform.

It was necessary to distinguish between intact and disintegrating cells. The cytological changes characteristic of cellular disintegration (lysis) are illustrated in P1. 4, fig. 3I-33 in comparison with a healthy cell (Pl. 4, fig. 30). Initially the nuclear fibrils condensed to form a loose network (Pl. 4, fig. $3 \mathrm{I}$ and 33, N). The cytoplasm was gradually replaced to a great extent by vacuole-like spaces $(S)$. Later the membranes, including those of the mesosomes, broke into fragments and often rounded off. Finally the cells consisted only of the wall and some membrane fragments (Glauert \& Hopwood, I960). The dense granules (Pl. 4, fig. 32), whose size varied from about 0.05 to $0.5 \mu \mathrm{m}$., also appeared to be symptomatic of the beginning of lysis, since they occurred almost exclusively in cells which showed all the signs of disintegration mentioned above.

Substrate mycelium before the appearance of the aerial mycelium (Pl. I, fig. I-4). This mycelium consisted of a loose network of branched and interconnected hyphae. The cell contents and wall appeared homogeneous. The white areas seen, for example, in Pl. I, fig. I are sectioning artifacts and not vacuoles. A few hyphae showed signs of disintegration (P1. I, fig. 2). Dense bodies, which are considered symptomatic of ageing hyphae, were only occasionally observed. The population of hyphae was densest near the agar surface (P1. I, fig. I), but, apart from a relatively thin top layer, it was sparse compared with the aerial mycelium.

White aerial mycelium shortly after its appearance (Pl. I, fig. 5-8). Impressions and sections revealed only closely packed hyphae with homogeneous cell contents and walls. Neither stages of sporulation nor disintegrating cells were seen. In contrast to the substrate hyphae, aerial hyphae often contained vacuoles (Pl. I, fig. 5, arrows) which at higher magnification were easily distinguished from sectioning artifacts. The population of hyphae was fairly dense and similar at all levels. Dense bodies were as rare as in the substrate mycelium. The boundary between the medium and the air was recognized by the many particles trapped within the agar (Pl. I, fig. 8, arrows); by definition this borderline indicated the transition from substrate to aerial mycelium.

White aerial mycelium, about one day after its appearance. Impressions revealed spores, singly or in chains, some of them germinating (Pl. 3, fig. 29), and a few aerial hyphae. However sections lacked spores and stages of sporulation; the loose spores were presumably washed off during fixation. Otherwise the aerial mycelium appeared the same as in younger colonies.

Pale grey aerial mycelium (P1. I, fig. 9-12). Impressions consisted almost entirely of spore chains and single spores; germinating spores were absent and hyphae were only rarely found.

In sections the aerial mycelium appeared very heterogeneous. Mature spores, mixed with some young hyphae, formed a top layer. Presumably most top spores which were not trapped between hyphae were washed off in the fixative. Owing to the hardness of their walls many spores folded during sectioning. Below the top layer was a deep zone of aerial hyphae and spores. In contrast to the top spores many 
were germinating (Pl. I, fig. Io, arrows) and none was folded; possibly all were at some stage of germination and therefore might have had softer walls. This would have allowed the fixative and embedding material to penetrate better, and account for the clearer cytological details of these spores compared with those of the hard-walled top spores. Disintegrating hyphae were only occasionally found.

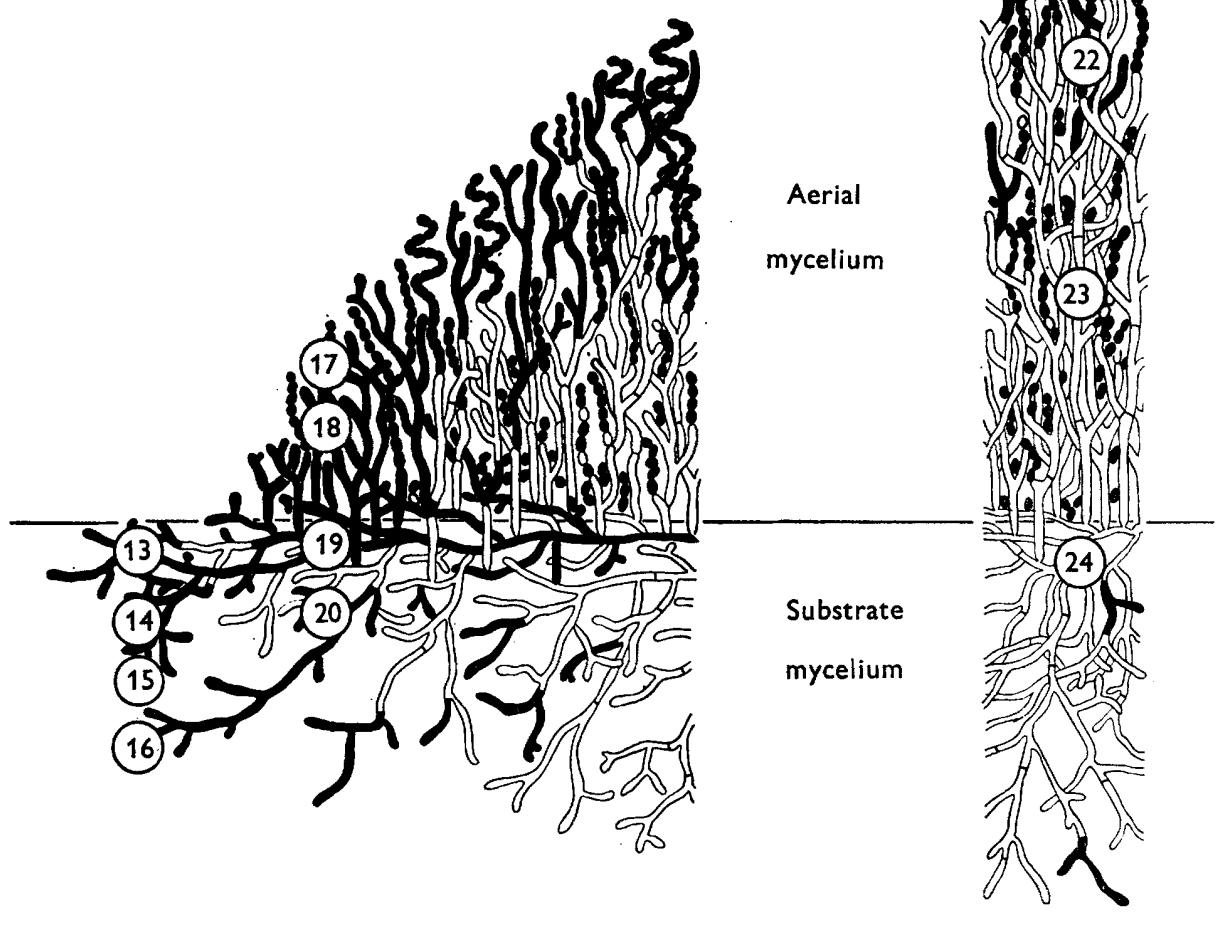

Fig. I. Idealized diagram of a vertical section through the centre of a colony at the climax of sporulation. Black represents intact cells and white disintegrating or completely lysed cells. Numbers indicate the positions where the pictures of Pl. 2 were taken.

Grey-brown aerial mycelium (P1. 2, fig. 13-24, and Fig. I). At this stage the colony had reached its climax of sporulation. Impressions contained practically only spores. In sections the mycelium appeared as a complicated and heterogeneous network of intact and disintegrating hyphae and all stages of sporulation. The spatial organization of the colony was studied in both the wild type and the auxotrophic mutant. Morphologically they were identical except that mutant colonies grown on minimal medium were much smaller. Vertical sections of parts of a mutant colony are shown in Plate 2. The regions photographed are indicated in Fig. I. On the top, near the centre of the aerial mycelium, most hyphae were intact (Pl. 2, fig. 2I and 22), but with increasing distance from the top, more disintegrating hyphae were encountered (Pl. 2, fig. 23). In the centre of the colony, below $50 \mu \mathrm{m}$. from the top, hardly any intact cells were found. (P1. 2, fig. 24.) At the edge of the colony, however, most hyphae appeared intact, 
including those of the substrate mycelium (Pl. 2, fig. 17-20). The edge of the aerial mycelium was rather sharp and the network of hyphae still very dense. In contrast, the edge of the substrate mycelium was very sparse and the number of hyphae decreased radially (Pl. 2, fig. I3-16). Although the colony was growing centrifugally the number of decaying hyphae was surprisingly high at the edge. The proportion of lysing cells increased towards the centre, where hardly any intact cells were found.

Old aerial mycelium: grey-brown with white patches. Old colonies which showed many symptoms of senescence consisted mainly of disintegrated hyphae and mature spores. The white patches were nests of young aerial mycelium which probably fed on the decaying part of the old colony over which they grew.

Spore forming and non-sporulating hyphae. The features seen in vertical sections of colonies of different ages suggest that the hyphae of the aerial mycelium have two alternative fates: spore formation and lysis. In negatively stained impressions of old colonies very many disintegrating hyphae were observed. Such hyphae were characterized by a lower electron density. Furthermore, pieces of liberated membrane were often seen outside the cell wall. Occasionally spore chains were attached to a nonsporulating part of a hypha (Pl. 3, fig. 25), the latter frequently showing signs of lysis. From these findings it is concluded that there are entirely sterile hyphae, and partly sterile hyphae, in which a non-sporulating 'stalk' bears spores at its tip, or in side branches along its axis. Sporulation was often initiated by coiling of the hyphal tip, but the formation of such helices did not seem obligatory since undisturbed impressions viewed with the phase-contrast microscope showed young straight spore chains alongside helical ones. It seems unlikely that the straight spore chains were produced by stretching due to the pressure of the coverslip, since Hopwood (1960) observed such a chain in a colony grown in an air space.

While the hyphal tip was coiling (Pl. 3, fig. 26) its cells were divided into spore-sized compartments by cross walls formed at regular distances (Pl. 3, fig. 27). Later the spores began to separate, the first sign of this being the formation of constrictions between the spore compartments (Pl. 3, fig. 28). Mature spore chains were held together by only a delicate envelope probably consisting of the fibrous sheath (surrounding the aerial hyphae) and parts of the parent cell wall (Wildermuth \& Hopwood, 1970). Therefore they easily broke into single spores. The number of spores within one chain was very variable. In impressions, short fragments containing only a few spores were found beside long rows sometimes consisting of more than 80 spores.

\section{DISCUSSION}

Spore germination in situ. This study revealed that spores developed immediately after the appearance of the aerial mycelium and that some of them began to germinate straight away. This behaviour of the young spores was repeatedly, although not always, observed. When the aerial mycelium turned pale grey the germinating cells were found under a top layer of 'resting' spores which was very thin in sections but might have been much thicker in reality since spores which were not trapped between hyphae tended to float off during fixation. At later stages no germinating spores could be observed. The reason for the immediate germination of the first batch of spores is unknown; possibly the relative humidity very close to the medium was high enough to initiate germination. 
Similarity with multicellular eukaryotes. Grey sporulating colonies were still growing radially; in a relatively thin surface layer numerous hyphal tips sporulated while overgrown by young hyphae. From the beginning the surface of the aerial mycelium was a steadily moving front of sporulating hyphae, leaving an enlarging zone of disintegrating cells behind them. Some of the lysing cells were basal 'stalks' of sporulating hyphae, but many had never borne spores.

These observations suggest that in Streptomyces colonies there are cells responsible for reproduction (spores) and hyphae which have a function only in an individual colony and have a limited lifespan. Therefore the colonies are differentiated into a soma and germ line comparable with those of multicellular eukaryotes. The fact that the colonies consist of at least three cell types (substrate hyphae, sterile and fertile aerial hyphae) organized in a mycelium makes the similarity even more obvious.

Dense granules. A striking feature of ageing cells was the appearance of large dense granules. These bodies, which were occasionally observed by Glauert \& Hopwood (I96I), are referred to as volutin granules. Glauert \& Brieger (I955) demonstrated that such dense bodies in Mycobacterium phlei were identical with metachromatic granules seen in the light microscope. They contained a large amount of metaphosphate, but their significance was not clear. In Streptomyces coelicolor they were related to cell lysis, although occasionally they were also found in healthy-looking cells, even in germinating spores. Baldacci, Gilardi \& Amici (1956) found similar granules in unstained whole mount preparations of disintegrating hyphae of Streptomycetes. However it is uncertain whether these corresponded to the granules observed in thin sections. During this study round dense granules were often seen in unfixed and unstained spores, but never in sections of spores. It is believed that the density of the granules seen in sections is due to uptake of osmium during fixation. Large 'osmiophilic granules' of about the same size appear in great numbers in chloroplasts of senescing leaves of Elodea, Phaseolus and Cucurbita (Ikeda \& Ueda, 1964; Barton, 1966; Butler, 1967). In spite of the similarity in morphology and appearance of the granules in these different organisms it is not certain whether they have the same significance; more has to be learned about their development and chemistry.

Part of this work was carried out at the Institute of Genetics, University of Glasgow. I wish to acknowledge the invaluable instruction afforded to me in the techniques of electron microscopy by Dr P. T. P. Oliver of that Institute. Thanks are due to Professor D. A. Hopwood for the organisms and for many helpful discussions during the preparation of the manuscript. I am indebted to Dr Audrey Glauert for a critical reading of this manuscript.

\section{REFERENCES}

Baldacci, E., Gilardi, E. \& AMICI, A. M. (I956). Il ciclo di vita degli attinomiceti osservato al microscopio elettronico. Giornale di Microbiologia 6, 512.

BARTON, R. (1966). Fine structure of mesophyll cells in senescing leaves of Phaseolus. Planta 7I, 3 I 4.

BRAdLeY, S. G. \& RitzI, D. (1968). Composition and ultrastructure of Streptomyces venezuelae. Journal of Bacteriology 95, 2358.

BRENNER, S. \& HoRNE, R. W. (1959). A negative staining method for high resolution electron microscopy of viruses. Biochimica et Biophysica Acta 34, 103.

BUtLeR, R. D. (1967). The fine structure of senescing cotyledons of cucumber. Journal of Experimental Botany 18, 535. 
ERIKSON, D. (1949). The morphology, cytology, and taxonomy of the actinomycetes. Annual Review of Microbiology 3, 23.

Glauert, A. M. \& Brieger, E. M. (I955). The electron-dense bodies of Mycobacterium phlei. Journal of General Microbiology 13, 310.

Glauert, A. M. \& Glauert, R. H. (1958). Araldite as an embedding medium for electron microscopy. Journal of Biophysical and Biochemical Cytology 4, $19 \mathrm{I}$.

Glauert, A. M. \& Hopwood, D. A. (1959). A membranous component of the cytoplasm in Streptomyces coelicolor. Journal of Biophysical and Biochemical Cytology 6, 515.

Glauert, A. M. \& Hopwood, D. A. (I960). The fine structure of Streptomyces coelicolor. I. The cytoplasmic membrane system. Journal of Biophysical and Biochemical Cytology 7, 479.

Glauert, A. M. \& Hopwood, D. A. (1961). The fine structure of Streptomyces violaceoruber $(S$. coelicolor). III. The walls of the mycelium and spores. Journal of Biophysical and Biochemical Cytology ro, 505 .

Glauert, A. M. \& ThORnley, M. J. (I966). Glutaraldehyde fixation of Gram-negative bacteria. Journal of the Royal Microscopical Society 85, 449.

HAGEDORN, H. (1960). Elektronenmikroskopische Untersuchungen an Streptomyces griseus (Krainsky). Zentralblatt für Bakteriologie, Parasitenkunde, Infektionskrankheiten und Hygiene (Abteilung II) $113,234$.

Hopwood, D. A. (1960). Phase contrast observations on Streptomyces coelicolor. Journal of General Microbiology 22, 295.

Hopwood, D. A. (1967). Genetic analysis and genome structure in Streptomyces coelicolor. Bacteriological Reviews 31, 373.

Hopwood, D. A. \& Glauert, A. M. (1960). The fine structure of Streptomyces coelicolor. II. The nuclear material. Journal of Biophysical and Biochemical Cytology 8, 267.

HORNE, R. W. (1965). The application of negative staining methods to quantitative electron microscopy Laboratory Investigation $\mathbf{1 4}$, 1054.

IKEDA, T. \& UEDA, R. R. (1964). Light and electron microscopical studies on the senescence of chloroplasts in Elodea leaf cells. Botanical Magazine, Tokyo 77, 336.

KLIENEBerger-Nobel, E. (1947). The life cycle of sporing Actinomyces as revealed by a study of their structure and septation. Journal of General Microbiology 1, 22.

KutzNer, H. J. \& WAKsman, S. A. (1958). Streptomyces coelicolor Müller and Streptomyces violaceoruber Waksman and Curtis, two distinctly different organisms. Journal of Bacteriology 78, 528.

Rancourt, M. W. \& Lechevalier, H. A. (1964). Electron microscopic study of the formation of spiny conidia in species of Streptomyces. Canadian Journal of Microbiology ro, 3I I I.

Ryter, A. \& Kellenberger, E. (I958). Étude au microscope electronique de plasma contenant de l'acide désoxyribonucléique. Zeitschrift für Naturforschung 136, 597.

Waksman, S. A. (1959). The Actinomycetes. I. Nature, Occurrence, and Activities. Baltimore: The Williams and Wilkins Co.

Wildermuth, H. \& Hopwood, D. A. (1970). Septation during sporulation in Streptomyces coelicolor. Journal of General Microbiology 60, 5I.

\section{EXPLANATION OF PLATES}

Plates I AND 2

Electron micrographs of parts of vertical sections of colonies of various physiological age. Note population density, intact and disintegrating cells, 'resting' and germinating spores. The scale mark represents $\mathrm{I} \mu \mathrm{m}$.

\section{Plate I}

Fig. I-4. Selected parts of the same section of a young colony, consisting only of substrate mycelium. Note disintegrated cell (arrow).

Fig. 5-8. Young colony with white aerial mycelium shortly after its appearance. Note vacuoles (Fig. 5, arrows) and boundary between substrate and aerial mycelium (Fig. 8, arrows).

Fig. 9-12. Colony with pale grey aerial mycelium. 'Resting' spores are mostly found in the top layer (Fig. 9), while germinating spores are seen in deeper zones (Fig. Io, arrows). Fig. I I was taken at the boundary between the two mycelia and Fig. I 2 represents substrate mycelium. 
Plate 2

Colony of autotrophic mutant 504 with grey brown aerial mycelium. The positions where the pictures were taken are shown in Fig. $I$ in text.

Fig. I3-16. Substrate mycelium beyond the aerial mycelium.

Fig. 17-20. Edge of the aerial mycelium.

Fig. 21-24. Centre of the colony.

\section{Plate 3}

Electron micrographs of negatively stained impressions of sporulation stages. The scale mark represents I $\mu \mathrm{m}$.

Fig. 25. Spore-chain with adjacent 'stalk' which is beginning to disintegrate.

Fig. 26. Coiled hyphal tip before septation.

Fig. 27. Hyphal tip after formation of sporulation septa. The constrictions between spores are not yet visible.

Fig. 28. Chain of mature spores. Note constrictions.

Fig. 29. Part of a spore chain from the top of white aerial mycelium, showing a germinating spore.

\section{Plate 4}

Electron micrographs of sections of aerial hyphae at various stages of disintegration. The scale mark represents $0.5 \mu \mathrm{m}$.

Fig. 30. Intact cell. $C W=$ cell wall; $F S=$ superficial layer (fibrous sheath); $C=$ cytoplasm; $N=$ nuclear material $P M=$ plasma membrane.

Fig. 3I. Aerial hypha showing the first signs of lysis. Note condensed fibrils of the nuclear material $(N)$, replacement of the cytoplasm by large vacuole-like spaces $(S)$ and the gaps between membranes. Fig. 32. Lysing cell with dense bodies.

Fig. 33. Advanced stage of lysis. $\quad N=$ nuclear material; $S=$ vacuole-like spaces. 
Journal of General Microbiology, Vol. 60, No. I

Plate I
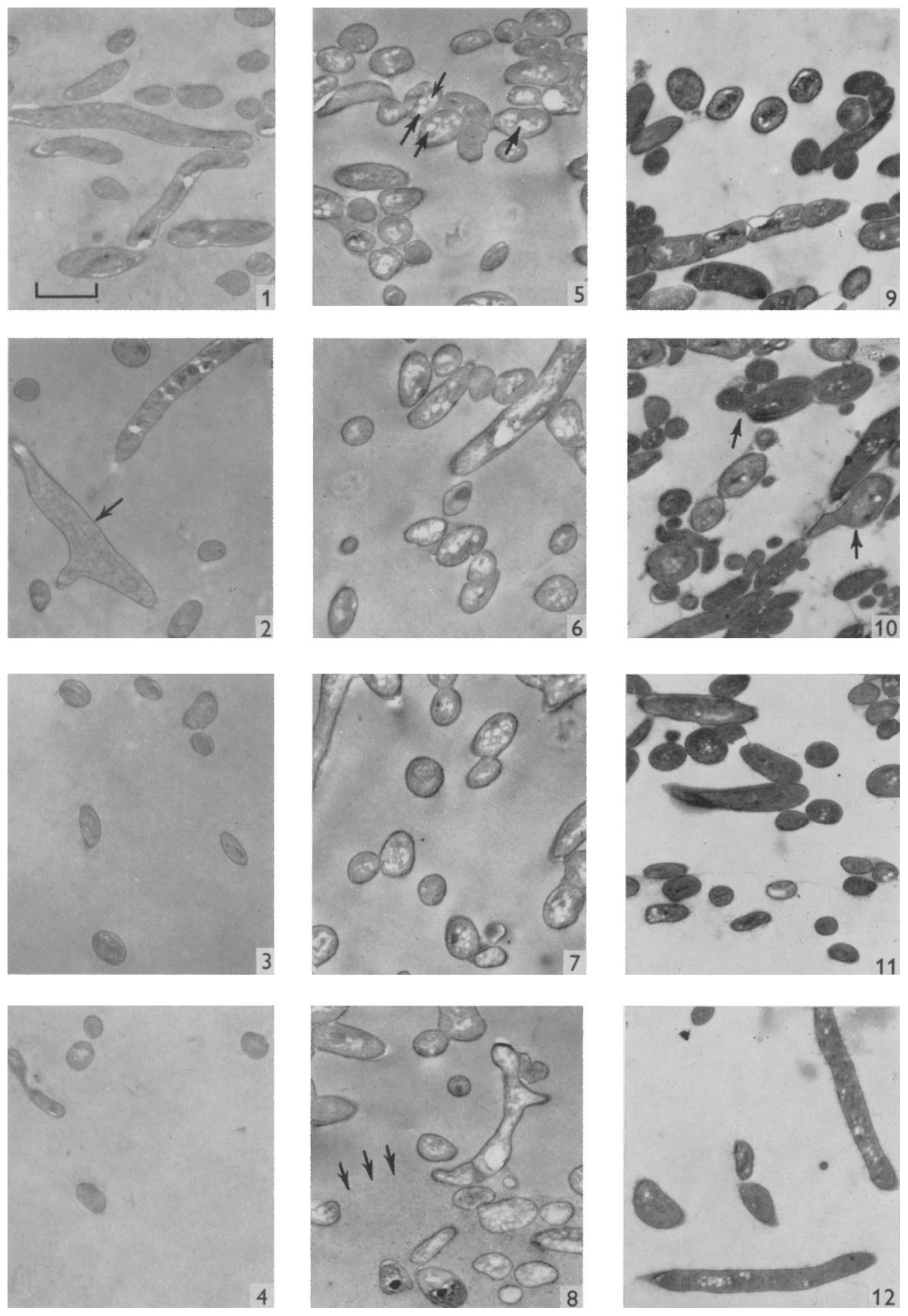

H. WILDERMUTH

(Facing p. 50) , 
Journal of General Microbiology, Vol. 60, No. I

Plate 2
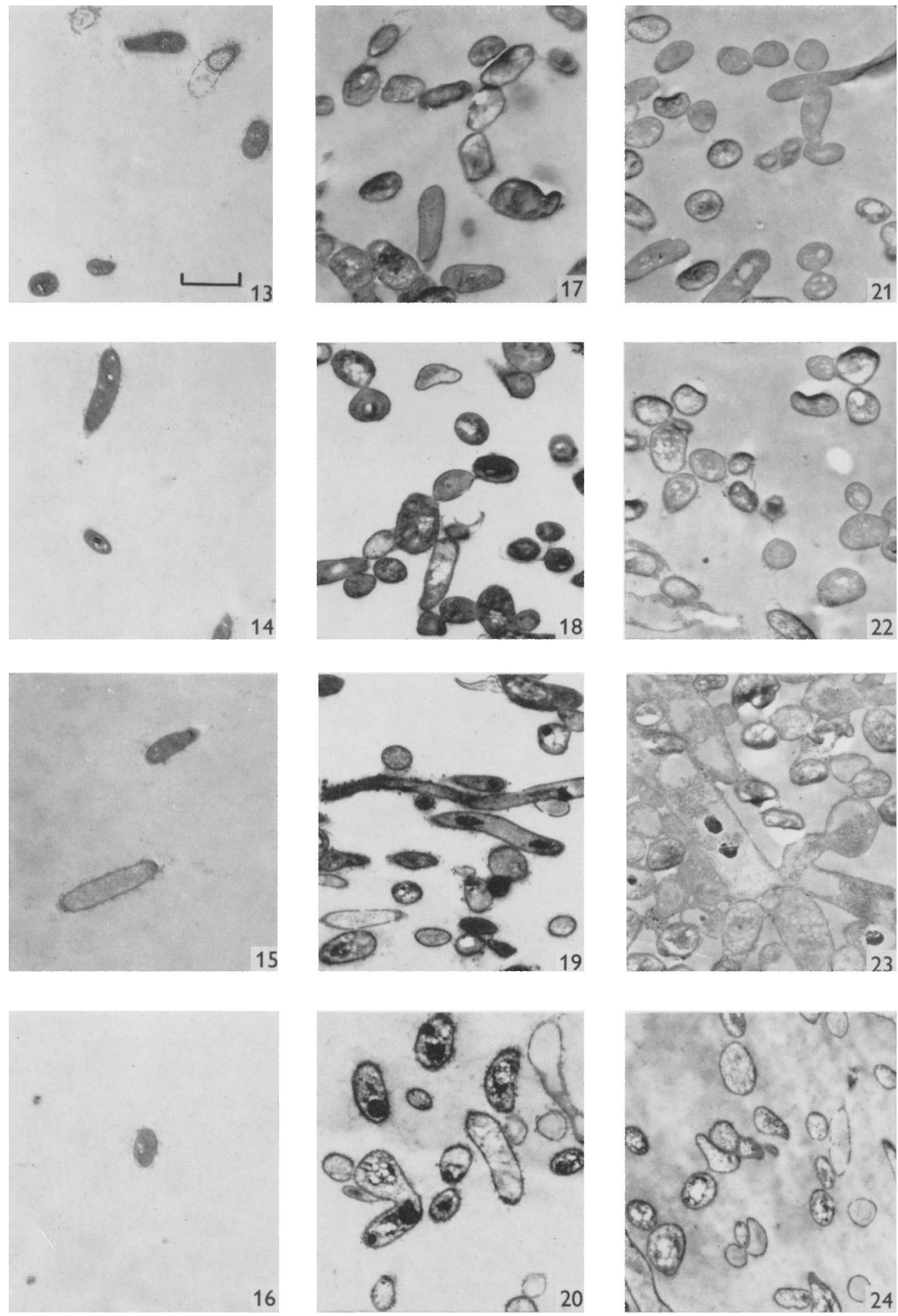

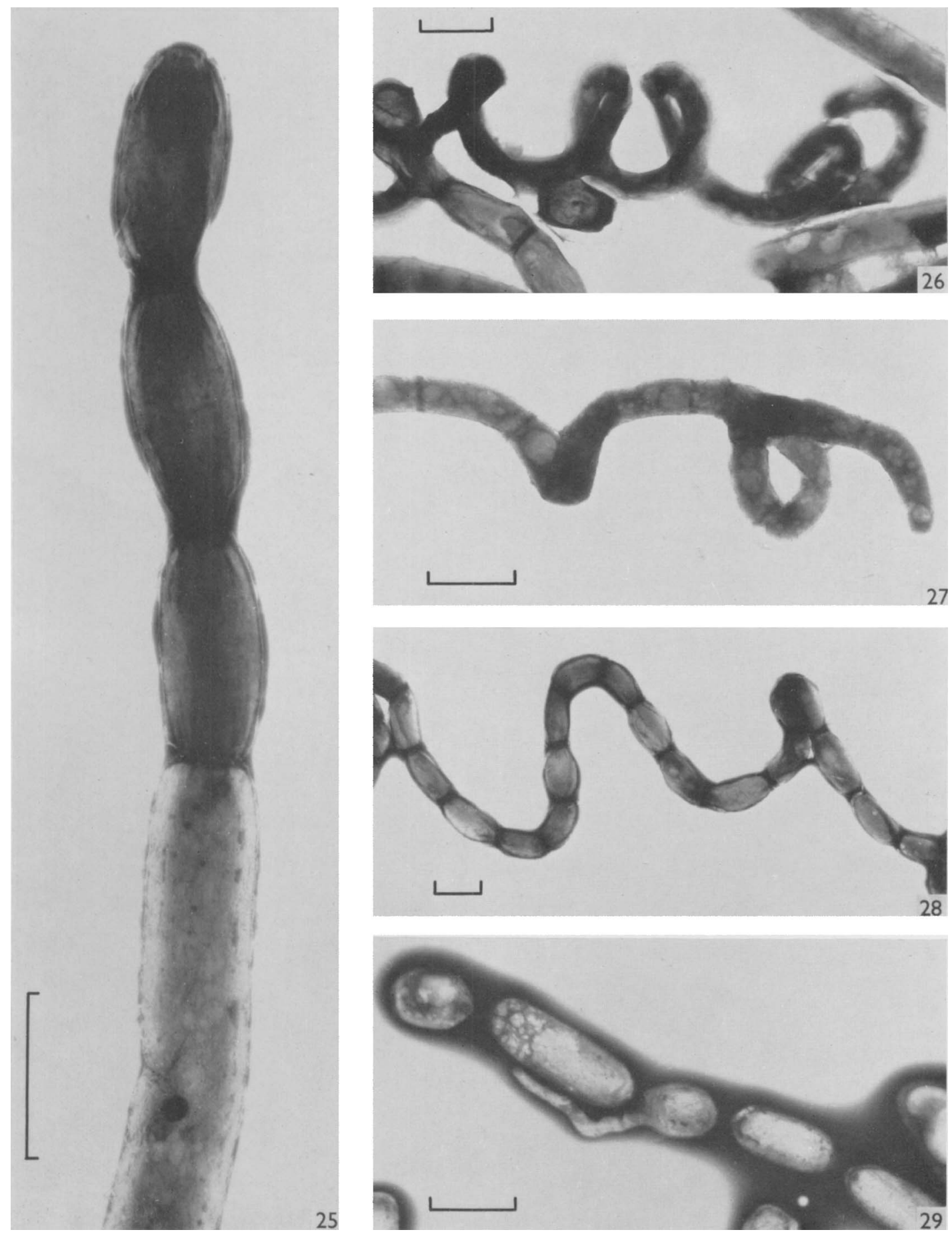

H. WILDERMUTH 
Journal of General Microbiology, Vol. 60, No. I

Plate 4
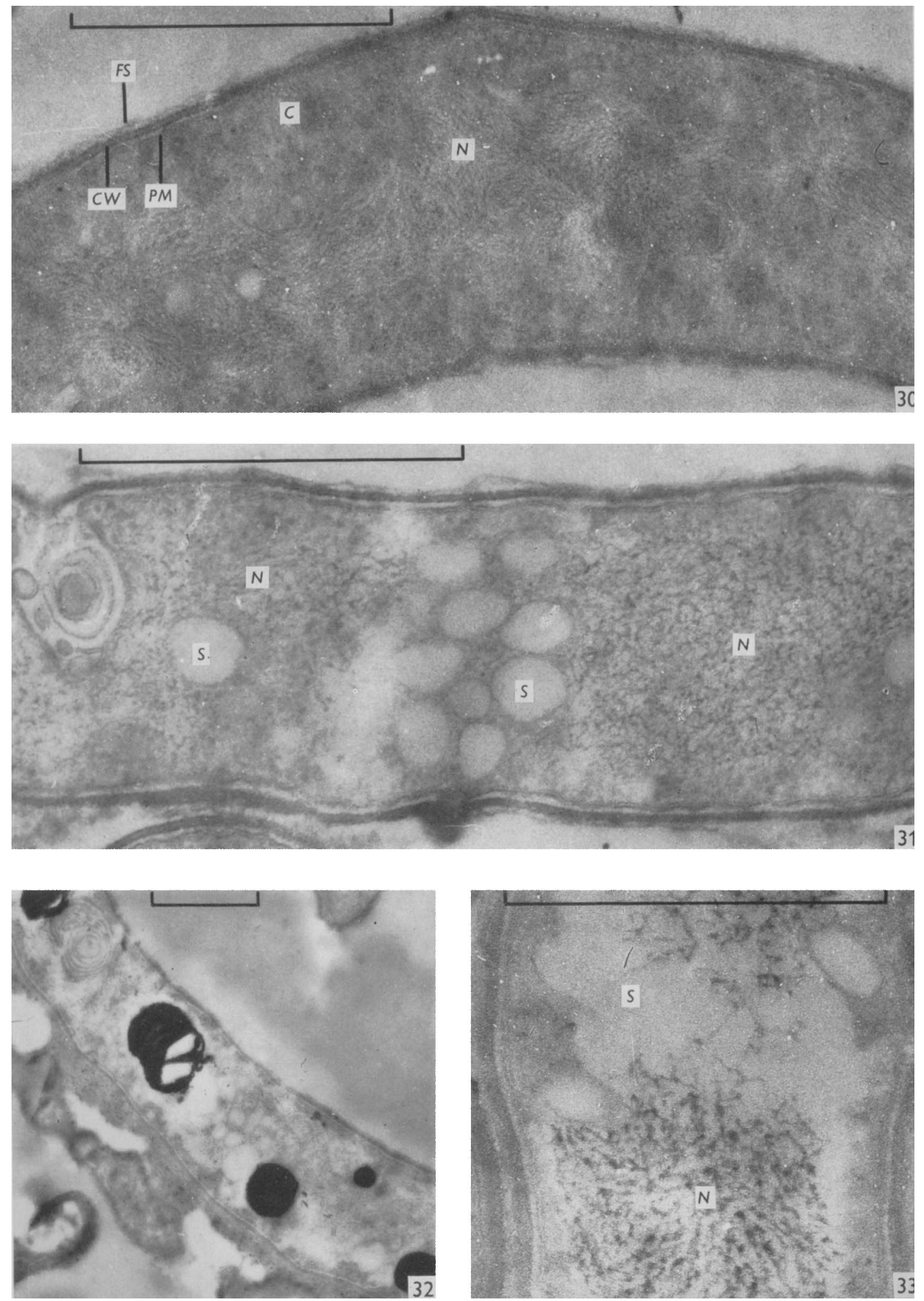

H. WILDERMUTH 